\title{
Conservative treatment for uncomplicated acute appendicitis in adults
}

\author{
Michele Pisano', Federico Coccolini', Elia Poiasina', Paolo Bertoli', Michela Giulii Capponi1 ${ }^{*}$, Eugenio Poletti', Richard Naspro² and \\ Luca Ansaloni ${ }^{1}$ \\ *Correspondence: mcapponi@hpg23.it \\ ${ }^{1} 1$ st General Surgery Unit, Papa Giovanni XXIII Hospital, Bergamo, Italy. \\ ${ }^{2}$ Urology Unit, Papa Giovanni XXIII Hospital, Bergamo, Italy.
}

\begin{abstract}
Background: Acute appendicitis is a very common disease with a life time risk of approximately 7-8\%. Worldwide, the standard of care for appendicitis is appendectomy that is to date considered generally a "routine and safe operation". However, the mortality rate of appendectomy is $0.7 \%$ and $2.4 \%$ in patients without and with perforation, respectively.

Aim: The paper aims to investigate the debate on surgical and non surgical treatment of acute uncomplicated appendicitis.

Methods: Pubmed and embase were queried for "acute appendicitis, antibiotics, surgery, conservative treatment, diagnosis". All prospective randomized studies, meta-analysis, systematic reviews and significant retrospective studies were retrieved. A brief analysis of single RCT and meta-analysis was conducted. Finally, the topic was developed by focusing on several clinical aspects.

Discussion and conclusions: The comparison of surgery and antibiotics, in terms of efficacy to treat acute appendicitis, is intrinsically complex due to the huge disparity of management and treatment options. After establishing an institutional validated clinical score, uncomplicated appendicitis in adult can be safely and successfully treated by antibiotic therapy an in-hospital setting if the patient is well informed. Nevertheless, outpatient antibiotic treatment cannot be proposed as a routine clinical practice. High risk patients should be treated with antibiotics whilst any treatment failure should be considered for mandatory surgery.
\end{abstract}

Keywords: Appendicitis, surgery, antibiotics, conservative treatment

\section{Background}

Acute appendicitis (AA) is a very common disease with a life time risk of $7-8 \%$, the highest incidence found in the second decade of life [1]. Although the aetiology of AA is still poorly understood, the most common hypothesis refers to appendix obstruction followed by impairment of wall appendix barrier and subsequent wall perforation and/or abscess formation [1]. However, some studies suggest that uncomplicated and complicated appendicitis are different entities that require a different treatment $[2,3]$.

Worldwide, the standard of care for appendicitis is appendectomy, to date considered generally a "routine and safe operation". However, the mortality rate of appendectomy ranges from 0.07 to $0.7 \%$ and from 0.5 to $2.4 \%$ in patients without and with perforation, respectively $[4,5]$. Although relatively low, mortality associated with an emergency appendectomy is age related and seven times higher than the general population matched per age and gender [4]. Meanwhile, overall post appendectomy complication rates are around $10-19 \%$ for AA without perforation and can reach $30 \%$ for perforated AA [6-8]. The peri-operative morbidity rate for removing a normal appendix in patients suspected of having AA is the same as that for intervention in non-perforated $A A[\mathbf{9}, \mathbf{1 0}]$.

However, a more detailed analysis of the literature shows that conservative management of AA has been considered a long time ago. In 1959 Coldrey reported a five-year experience of 471 unselected patients, with non operative treatment of AA. The Authors report low morbidity and mortality rates [11]. In 1977, 425 unselected patients were treated by traditional Chinese medicine and antibiotic treatment and recurrent appendicitis was described in 7/100 patients [12].

The present review aims to review existing data on the conservative management of uncomplicated AA using antibiotic treatment.

\section{Brief analysis of randomized controlled trials ( $r c t)$} and meta-analysis (ma)

1. The Eriksson study: presented a very small population with only 20 patients recruited per arm. One patient in the antibiotic group underwent surgery [13].

2. The Styrud study: was a well-designed study. However, the diagnosis was strictly linked to surgeon suspicion, women were excluded and no common endpoint for both arms was established. In both groups, the perforation rate was $5 \%$. Out of the patients in the antibiotic arm, $86 \%$ improved without surgery, while 17 patients (12\%) required surgery within 24 hours. The diagnosis was correct in $97 \%$ of the cases. The 1 year recurrence rate was 14\% [14].

3. The Hasson study: the diagnosis looked strictly linked to surgeon's skill; the randomization was related to the date

(C) 2013 Giulii Capponi et al; licensee Herbert Publications Ltd. This is an Open Access article distributed under the terms of Creative Commons Attribution License (http://creativecommons.org/licenses/by/3.0). This permits unrestricted use, distribution, and reproduction in any medium, provided the original work is properly cited. 
of birth; the subjective diagnostic criteria could explain that 96 patients from the antibiotic group were transferred to the surgical group and 10 patients form the surgical group went into the antibiotic group. Moreover, the primary endpoints were largely different between the two arms of the study [15].

4. The Malik study: was withdrawn by editors in October 2011 because a portion of data was already published by Eriksson [16].

5. The Vonns study: $\mathrm{CT}$ criteria used to define appendicitis are not worldwide accepted. Furthermore, the use of CT scan for the diagnosis of appendicitis is uncommon even in developed countries leading to non-reproducible protocols. Due to the use of CT scan as first step, we can suspect some delays in antibiotics administration.

Furthermore, the route of antibiotic administration is different among groups. As the Authors underline, the use of amoxicillin plus clavulanic acid as a single agent could explain the higher rate of failure compared to other trials. The primary endpoint is evaluation of post treatment peritonitis. However, 21 patients randomized to surgery showed signs of peritonitis during the operation despite the previous CT scan diagnosis of uncomplicated AA. These patients were excluded from analysis while a similar percentage of patients has been included in the antibiotic arm [17].

Conflicting conclusions arise also from the metaanalysis (MA), surely a useful statistical method to overcome the potential limitations and biases that arise from a single study. However, the potential pitfalls of such analysis, which is often based on the combination of poor studies, are well known. Briefly, we list the results of the most recent (2009-2012) MA available from the literature:

1. The Ansaloni study: although a non-surgical approach in AA can reduce overall complication rate, the lower efficacy prevents antibiotic treatment from being a viable alternative to surgery. Since only a small number of RCTs of poor methodological quality are available, welldesigned RCTs are needed for further investigation [18].

2. The Liu study: In some cases, antibiotic treatment may fail, thus there is a risk of AA recurrence. However, surgically treated patients, including those with the potential for spontaneous resolution and those with a normal appendix, are exposed to the risks of operative morbidity and mortality. Antibiotic therapy can surely significantly provide lower complication rates. Prospective randomized studies are urgently needed to conclusively define the roles of appendectomy and antibiotic treatment in the management of uncomplicated acute appendicitis [19].

3. The Wilms study for the Cochrane Collaboration Group: the upper bound of the $95 \% \mathrm{Cl}$ of ABT for cure within two weeks without major complications crosses the $20 \%$ margin of appendectomy, so the outcome is inconclusive. Furthermore, the quality of the studies was low to moderate and therefore the results should be interpreted with caution and definite conclusions cannot be drawn. Therefore, the Authors conclude that appendectomy remains the standard treatment for acute appendicitis. Antibiotic treatment might be used as an alternative treatment in a good quality RCT or in specific patients or in conditions were surgery is contraindicated [20].

4. The Varadhan study: antibiotics are both effective and safe as primary treatment for patients with uncomplicated acute appendicitis. Initial antibiotic treatment deserves consideration as a primary treatment option for early uncomplicated appendicitis [21].

\section{Safety: mortality and morbidity}

Mortality rates following appendectomy range from 0,07 to $0.7 \%$ and from 0.5 to $2.4 \%$ for appendicitis without or with perforation, respectively [4]. However, mortality is not strictly linked to the degree of inflammation/complication, but it is also related to the trauma of anaesthesia and surgery $[22,23]$. Blomqvist et al., published a very interesting epidemiological study of appendectomies performed in Sweden. In this study, appendectomies performed for unspecific abdominal pain and for other diagnosis showed a case fatality rate of 1.87 and 9.89 respectively. For patients operated for suspected AA but discharged with no-specific abdominal pain diagnosis, the cause of death was non-abdominal in $70 \%$ of cases. A more recent retrospective analysis conducted using data from the US National Inpatient Sample from 1998 to 2007 described the rate of negative appendectomy of $11.83 \%$ and among these patients mortality was $1.07 \%$ [24].

Age and co-morbidities increase the percentages of mortality after appendectomy for appendicitis up to $0.1 \%, 2.6 \%, 6.8 \%$, and $16.4 \%$ in patients aged $40,70,80,90$, respectively [4].

On the contrary, antibiotic therapy does not appear to be a harmful treatment option as well demonstrated in the literature with case series, RCT and MA. Coldrey reported one death among 471 patients treated conservatively in 1959 $[11,16]$. No randomized trial has been able to demonstrate that antibiotic failure following surgical delay is associated with increased mortality or morbidity compared to primary surgery. The safety of delayed appendectomy, defined as 30-days outcomes, has been also confirmed by Ingraham in a retrospective study of 32,782 patients [25].

Although some clinical trials have failed to well define complications $[13,14,18]$, the morbidity scenario ranges from superficial wound infections to cardiac complication related to surgery and anaesthesia. Hansson found a significantly lower rate of major complications in the antibiotic group comparing to surgery both in the intention to treat either in the protocol analysis: $5.4 \%$ vs $10.8 \%$ and $2.5 \%$ vs $10 \%$, respectively. Minor complications didn't differ among groups [15]. On the other hand, according to Vons, post-treatment peritonitis likely correlated with antibiotic therapy, however without reaching statistical significance [17]. Generally, in 
case of non-perforated appendicitis, post appendectomy morbidity rates range between 10 and $20 \%$, reaching $30 \%$ when perforation occurs.

Finally, one specific complication of surgery is peritoneal adhesion formation, even with the laparoscopic approach. Almost $1.5 \%$ of patients who underwent surgery for acute appendicitis requires surgery within the following 30 years due to bowel obstruction from appendectomy related peritoneal adhesions $[4,15,26]$.

\section{Efficacy}

The comparison of surgery and antibiotics in terms of efficacy to treat $A A$, is intrinsically complex due to the huge disparity of treatments available. Consequently, we attempted to summarize the terms of the debate.

Hypothetically, surgery can treat acute appendicitis in $100 \%$ of cases with the mortality and morbidity rate already described. Primary antibiotic failure has been variously defined by different authors leaving many decisions to personal judgement even in large clinical trials. As a consequence, the rate of failure within 48 hours ranges from $5 \%$ to $47 \%$ [18]. When primary failure occurs, all authors agree for surgery as no mortality or significant morbidity is added in case of delayed surgery.

Recurrence of appendicitis after appendectomy is quite impossible. However the inflammation of a long $(>0.5 \mathrm{~cm})$ residual appendiceal stump has been described in 61 cases from 1945 to now [27].

First-year recurrence rate of $A A$ successful treated by antibiotic ranges between 10 and 15\% [18]. Higher percentages have been reported in the previous study of Eriksson $[13,18]$ and in a recent prospective study by Vons et al., $(36.8 \%$ and $26 \%$ respectively) [17].

Due to the rate of recurrence, according to the Ansaloni meta-analysis, the clinical effectiveness favours surgery. However, the Cochrane review showed that, due to the lowmoderate quality of studies, only minor complications in the two groups can be truly compared [20].

Surprisingly, a different interpretation of the same studies has been published in the British Medical Journal and the authors conclude that antibiotics are both effective and safe as primary treatment for patients with uncomplicated AA [21].

\section{Potential advantages of non-surgical treatment}

Acute appendicitis successfully treated by antibiotics still remains a potential source of recurrent appendicitis. On the other hand, post-operative wound infections and post appendectomy bowel obstruction, even after 30 years from appendectomy, have been described. What is the most important issue for the single patient? Probably there is not a right answer to this dilemma.

Historically, the link between appendicitis and surgery has been necessarily challenged by antibiotics in a poor surgical scenario such as in 9 US submariners [28] and in patients aboard Soviet ships treated at sea. In the latter Gurin et al., by reviewing the conservative treatment outcomes in 252 patients with AA on vessels of the Kalingrad fishing industry from 1975 to 1987 , reported a recovery rate of $84.1 \%$ with the only use of antibiotics [29].

Thus, antibiotics offer the opportunity to treat AA even when surgical resources are not easily available such as in developing countries.

Moreover, worldwide health systems everyday carefully assessing the cost effectiveness of all medical actions. A significant difference in hospital costs was reported by Hansson et al., with a reduction in expenses of $25-50 \%$ in the antibiotic group compared to surgery [15].

The antibiotic approach offers the opportunity to avoid "white" appendectomies and thus allowing a more correct use of health resources even in the busy scenario of developed countries.

The same rationale of approach can be useful in the setting of surgically high risk patients [20,30]. In 2012 Tugnoli and collaborators, from Italy, reported the preliminary results of a prospective observational study on the non-operative treatment for acute appendicitis (NOTA-study): they found a relapse rate of $A A$ at six months of $8.3 \%$ : patients with new episode of AA mandate surgery [31,32].

Finally, there is no doubt that in case of success (approximately $80 \%$ ) the antibiotic treatment can eliminate the mortality and morbidity risk related to surgery.

\section{The antibiotic choice}

Antimicrobial therapy plays an integral role in the management of intra-abdominal infections, especially in critically ill patients who require immediate empiric antibiotic therapy. An insufficient or otherwise inadequate antimicrobial regimen is one of the variables most strongly associated with unfavourable outcomes $[33,34]$. In the treatment of AA, antibiotic therapy remains a cornerstone but surgery is still considered the gold standard $[17,18,30]$. Many different antibiotic regimen have been used to treat AA and many different studies have been started to compare different antibiotics regimen in the treatment of localized or diffuse peritonitis [35].

Definitive recommendations regarding the optimal antibiotic treatment of AA have not been established yet. Several types of antibiotics and combinations of them which can be used in the treatment of AA have been proposed $[13,14]$. The possibility to effectively treat AA and intra-abdominal infections in general with a mono-therapy has made triple regimen antibiotic treatment obsolete $[30,36]$. Moreover, the possibility to administer oral antibiotics, which are absorbed so efficiently through the gastrointestinal tract allows to treat many serious infections (acute diverticulitis and AA with phlegmon or abscess) on an outpatient basis with efficacy equal to intravenous regimens [36-38]. Generally, in the majority of treatment protocols, antibiotics are administered intravenously for 24-48 h. Patients are then discharged with 
Pisano et al. Emergency Medicine \& Health Care 2013,

oral antibiotics for approximately $7-10$ days $[13,14,18]$.

The two main obstacles to the antibiotic treatment of AA are the increasing antibiotic resistances and allergies. The frequent use, and several times the misuse of antibiotics in the treatment of intra-abdominal infections is leading to an increase of the number of bacteria resistant to the different lines of antibiotics. The choice of the therapy regimen in each patient should be driven by the necessity to defeat the infection without creating a new resistant clone of bacteria [39]. Surgeons should know the different possibilities in antibiotics regimens and each time should choose the more adequate.

\section{In favour of surgery}

The first obvious advantage is that surgery reduces risk of recurrence with a small percentage of mortality and morbidity.

The second advantage is that surgical intervention offers the opportunity to "take a look inside the abdomen". Although appendectomy is not an official diagnostic tool for malignancy, carcinoid is found in 3-7/1000 appendectomies and colon cancer in $0.85 \%$ cases $[\mathbf{4 0 , 4 1 ]}$.

Probably, we should compare the risk of missing tumours with the $0.07-0.7 \%$ mortality risk of appendectomy performed for AA without perforation.

The third advantage arises from the reduced use of antibiotics. Whilst antibiotics are generally stopped after the removal of a normal or phlegmonous appendix, patients treated by antibiotic therapy alone will receive a longer course of drugs. Thus, the increasing risk of the antibiotics resistance is theoretically reduced by the surgery.

\section{Weak points in the analysis of the literature}

Despite appendicitis has been largely described, the preoperative diagnosis of AA is still not very well defined and clinical expertise is required. The rate of white appendix as well the rate of different diagnosis could be used to estimate the diagnostic dilemma.

CT scan offers the best tool in obtaining preoperative diagnosis, however distinction between uncomplicated and complicated AA remains difficult even with multiple-detector CT scans $[17,42,43]$. Despite the accuracy of $C T$ scan, its routine use in the appendicitis settings is poor even in developed countries and in the only randomized study by Vons.

Moreover,the usefulness of $\mathrm{CT}$ scan in the management of AA has been criticized because it can potentially delay the immediate intravenous antibiotic ("door to needle time") which could play a role in the outcome of patients treated by antibiotic alone [44-46].

Alvarado proposed a clinical score which has been largely adopted and sometimes modified locally to became simpler. More recently, Andersson proposed a new clinical score which has been proven to outperform the Alvarado score [47]. According to this diagnostic tool, patients are divided in three groups. In Group 1 (score 0-4) patients with a very low probability to suffer of AA (sensibility and specificity), in Group 2 (score 5-8) patients with an higher probability to suffer of AA (sensibility and specificity), in Group 3 (score 9-12) patients with a very high probability to suffer of AA.

\section{Conclusions}

The surgical treatment of AA can be universally considered a "mile stone" in modern medicine. Nevertheless, the literature has shown an unexpected worldwide interest in reconsidering this dogma as demonstrated by five RCT in the last fifteen years and four MA presented in the last 2 years.

The comparison of surgery and antibiotic therapy is still a challenging issue. Should we compare the rate of early failure in the antibiotic arm with the rate of white appendicitis? Or should we compare the recurrence rate of antibiotic treated appendicitis within 30-days and long-time morbidity of surgery? Furthermore, how should we consider occasionally discovered tumours in the appendicitis specimen? And finally, how to analyze the risk of antibiotic resistance?

In order to reduce the rate of "white appendicitis" and misdiagnosis there is the need to improve the diagnostic power. Therefore, we suggest to adopt at least a single institutional clinical diagnostic tool and algorithm. US, when available, could represent an extension, but not a substitution, of a clinical score and assessment. CT scan should be used in difficult cases to help pin point diagnosis, in dedicated centres. The comparison of antibiotic and surgery needs an homogenous and more objective patient selection and guidelines. Some advantages and some disadvantages are intrinsic in the treatment choice and cannot be compared. Furthermore, currently it is difficult to correctly assess the risk-benefit ratio between recurrent rate of appendicitis at one year with the potential risk of post-operative bowel obstruction.

Surgical mortality should be also compared to antibiotic mortality and morbidity. The peculiar characteristics of single treatment cannot be scientifically compared.

There are In our opinion, after establishing an institutional validated clinical score, uncomplicated appendicitis in adults can be safely and successfully treated by antibiotics in an inhospital scenario if the patient accepts pro and cons and is correctly counselled. On the other hand, outpatient antibiotic treatment cannot be proposed as a clinical standard practice. High risk patients should be treated by antibiotics whilst surgery is to be considered mandatory after conservative treatment failure.

In conclusion, our clinical decision making currently derives from RCT and MA that present multiple limitaitons and biases. Therefore, we designed the ASAA study: an ongoing multicentre, prospective, randomized study comparing antibiotic therapy and surgery [48]. Hopefully, the data will provide a better insight into the current management of AA.

\section{Competing interests}

The authors declare that they have no competing interests. 
Pisano et al. Emergency Medicine \& Health Care 2013,

Authors' contributions

\begin{tabular}{|l|c|c|c|c|c|c|c|c|}
\hline Authors' contributions & MP & FC & EP & PB & MGC & EP & RN & LA \\
\hline Research concept and design & $\sqrt{ }$ & -- & -- & -- & -- & -- & -- & $\sqrt{ }$ \\
\hline Collection and/or assembly of data & -- & -- & $\sqrt{ }$ & $\sqrt{ }$ & $\sqrt{ }$ & $\sqrt{ }$ & -- & -- \\
\hline Data analysis and interpretation & $\sqrt{ }$ & $\sqrt{ }$ & $\sqrt{ }$ & -- & -- & -- & -- & $\sqrt{ }$ \\
\hline Writing the article & $\sqrt{ }$ & $\sqrt{ }$ & -- & -- & $\sqrt{ }$ & -- & $\sqrt{ }$ & -- \\
\hline Critical revision of the article & -- & -- & $\sqrt{ }$ & -- & $\sqrt{ }$ & -- & -- & $\sqrt{ }$ \\
\hline Final approval of article & $\sqrt{ }$ & $\sqrt{ }$ & $\sqrt{ }$ & -- & $\sqrt{ }$ & -- & -- & $\sqrt{ }$ \\
\hline Statistical analysis & -- & -- & $\sqrt{ }$ & -- & -- & -- & -- & -- \\
\hline
\end{tabular}

Acknowledgement

We would like to thank our Collegues Dr Luca Campanati, Dr Nicola Colaianni Dr, Marco Lotti, Dr Stefano Magnone, Dr Roberto Manfredi, Dr Dario Piazzalunga, 1st General Surgery Unit, Papa Giovanni XXIII Hospital, Bergamo, Italy.

\section{Publication history}

Editor: Salomone Di Saverio, University of Bologna, Italy. EIC: Joseph Varon, The University of Texas Medical Branch , USA. Received: 24-Jul-2013 Revised: 10-Sep-2013

Accepted: 16-Sep-2013 Published: 20-Sep-2013

\section{References}

1. Addiss DG, Shaffer N, Fowler BS and Tauxe RV. The epidemiology of appendicitis and appendectomy in the United States. Am J Epidemiol. 1990; 132:910-25. | Article | PubMed

2. Mason RJ. Surgery for appendicitis: is it necessary? Surg Infect (Larchmt). 2008; 9:481-8. | Article | PubMed

3. Andersson RE. The natural history and traditional management of appendicitis revisited: spontaneous resolution and predominance of prehospital perforations imply that a correct diagnosis is more important than an early diagnosis. World J Surg. 2007; 31:86-92. | Article | PubMed

4. Blomqvist $\mathrm{P}$, Ljung $\mathrm{H}$, Nyren $\mathrm{O}$ and Ekbom $\mathrm{A}$. Appendectomy in Sweden 1989-1993 assessed by the Inpatient Registry. J Clin Epidemiol. 1998; 51:859-65. | Article | PubMed

5. Margenthaler JA, Longo WE, Virgo KS, Johnson FE, Oprian CA, Henderson WG, Daley J and Khuri SF. Risk factors for adverse outcomes after the surgical treatment of appendicitis in adults. Ann Surg. 2003; 238:59-66. | Article | PubMed Abstract | PubMed Full Text

6. Hale DA, Molloy M, Pearl RH, Schutt DC and Jaques DP. Appendectomy: a contemporary appraisal. Ann Surg. 1997; 225:252-61. | Article | PubMed Abstract | PubMed Full Text

7. Colson M, Skinner KA and Dunnington G. High negative appendectomy rates are no longer acceptable. Am J Surg. 1997; 174:723-6; discussion 726-7. | Article | PubMed

8. Guller U, Jain N, Peterson ED, Muhlbaier LH, Eubanks S and Pietrobon R. Laparoscopic appendectomy in the elderly. Surgery. 2004; 135:479-88. Article I PubMed

9. Bijnen CL, Van Den Broek WT, Bijnen AB, De Ruiter P and Gouma DJ. Implications of removing a normal appendix. Dig Surg. 2003; 20:115-21. | Article | PubMed

10. Flum DR and Koepsell T. The clinical and economic correlates of misdiagnosed appendicitis: nationwide analysis. Arch Surg. 2002; 137:799-804; discussion 804. | Article | PubMed

11. Coldrey E. Five years of conservative treatment of acute appendicitis. $J$ Int Coll Surg. 1959; 32:255-261.

12. Combined traditional Chinese and western medicine in acute appendicitis. Chin Med J (Engl). 1977; 3:266-9. | Article | PubMed

13. Eriksson $S$ and Granstrom L. Randomized controlled trial of appendicectomy versus antibiotic therapy for acute appendicitis. $\mathrm{Br} J$
Surg. 1995; 82:166-9. | Article | PubMed

14. Styrud J, Eriksson S, Nilsson I, Ahlberg G, Haapaniemi S, Neovius G, Rex L, Badume I and Granstrom L. Appendectomy versus antibiotic treatment in acute appendicitis. a prospective multicenter randomized controlled trial. World J Surg. 2006; 30:1033-7. | Article | PubMed

15. Hansson J, Korner U, Khorram-Manesh A, Solberg A and Lundholm K. Randomized clinical trial of antibiotic therapy versus appendicectomy as primary treatment of acute appendicitis in unselected patients. $\mathrm{Br} J$ Surg. 2009; 96:473-81. | Article | PubMed

16. Malik AA and Bari SU. Conservative management of acute appendicitis J Gastrointest Surg. 2009; 13:966-70. | Article | PubMed

17. Vons C, Barry C, Maitre S, Pautrat K, Leconte M, Costaglioli B, Karoui M, Alves A, Dousset B, Valleur P, Falissard B and Franco D. Amoxicillin plus clavulanic acid versus appendicectomy for treatment of acute uncomplicated appendicitis: an open-label, non-inferiority, randomised controlled trial. Lancet. 2011; 377:1573-9. | Article | PubMed

18. Ansaloni L, Catena F, Coccolini F, Ercolani G, Gazzotti F, Pasqualini E and Pinna AD. Surgery versus conservative antibiotic treatment in acute appendicitis: a systematic review and meta-analysis of randomized controlled trials. Dig Surg. 2011; 28:210-21. | Article | PubMed

19. Liu K and Fogg L. Use of antibiotics alone for treatment of uncomplicated acute appendicitis: a systematic review and metaanalysis. Surgery. 2011; 150:673-83. | Article | PubMed

20. Wilms IM, de Hoog DE, de Visser DC and Janzing HM. Appendectomy versus antibiotic treatment for acute appendicitis. Cochrane Database Syst Rev. 2011; 11:CD008359. | Article | PubMed

21. Varadhan KK, Neal KR and Lobo DN. Safety and efficacy of antibiotics compared with appendicectomy for treatment of uncomplicated acute appendicitis: meta-analysis of randomised controlled trials. BMJ. 2012; 344:e2156. | Article | PubMed Abstract | PubMed Full Text

22. Wen SW and Naylor CD. Diagnostic accuracy and short-term surgical outcomes in cases of suspected acute appendicitis. CMAJ. 1995; 152:1617-26. | Article | PubMed Abstract | PubMed Full Text

23. McDonald PJ, Royle GT, Taylor I and Karran SJ. Mortality in a university surgical unit: what is an avoidable death? $J R$ Soc Med. 1991; 84:213-6. | PubMed Abstract | PubMed Full Text

24. Seetahal SA, Bolorunduro OB, Sookdeo TC, Oyetunji TA, Greene WR, Frederick W, Cornwell EE, 3rd, Chang DC and Siram SM. Negative appendectomy: a 10-year review of a nationally representative sample. Am J Surg. 2011; 201:433-7. | Article | PubMed

25. Ingraham AM, Cohen ME, Bilimoria KY, Ko CY, Hall BL, Russell TR and Nathens AB. Effect of delay to operation on outcomes in adults with acute appendicitis. Arch Surg. 2010; 145:886-92. | Article | PubMed

26. Andersson RE. Small bowel obstruction after appendicectomy. Br J Surg. 2001; 88:1387-91. | Article | PubMed

27. Subramanian $A$ and Liang MK. A 60-year literature review of stump appendicitis: the need for a critical view. Am J Surg. 2012; 203:503-7. | Article I PubMed

28. Adams ML. The medical management of acute appendicitis in a nonsurgical environment: a retrospective case review. Mil Med. 1990; 155:345-7. | Article | PubMed

29. Gurin NN, Slobodchuk Iu S and Gavrilov lu F. [The efficacy of the conservative treatment of patients with acute appendicitis on board ships at sea]. Vestn Khir Im I/ Grek. 1992; 148:144-50. | Article | PubMed

30. Sakorafas GH, Mastoraki A, Lappas C, Sampanis D, Danias N and Smyrniotis V. Conservative treatment of acute appendicitis: heresy or an effective and acceptable alternative to surgery? Eur J Gastroenterol Hepatol. 2011; 23:121-7. | Article | PubMed

31. Tugnoli G, Giorgini E, Biscardi A, Villani S, Clemente N, Senatore G, Filicori F, Antonacci N, Baldoni F, De Werra C and Di Saverio S. The NOTA study: non-operative treatment for acute appendicitis: prospective study on the efficacy and safety of antibiotic treatment (amoxicillin and clavulanic acid) in patients with right sided lower abdominal pain. BMJ Open. 2011; 1:e000006. doi:10.1136/bmjopen-2010-000006| Article | PubMed Abstract | PubMed Full Text 
32. Di Saverio S, Coccolini F, Pisano M, Catena F, Jovine E, Tugnoli G and Ansaloni L. Re: Male gender is a risk factor for recurrent appendicitis following nonoperative treatment. World J Surg. 2012; 36:486-7. I Article I PubMed

33. Paul M, Shani V, Muchtar E, Kariv G, Robenshtok E and Leibovici L. Systematic review and meta-analysis of the efficacy of appropriate empiric antibiotic therapy for sepsis. Antimicrob Agents Chemother. 2010; 54:4851-63. | Article | PubMed Abstract | PubMed Full Text

34. Dellinger RP, Levy MM, Carlet JM, Bion J, Parker MM, Jaeschke R, Reinhart K, Angus DC, Brun-Buisson C and Beale R et al. Surviving Sepsis Campaign: international guidelines for management of severe sepsis and septic shock: 2008. Crit Care Med. 2008; 36:296-327. | Article | PubMed

35. Coccolini F, Catena F, Ansaloni L, Ercolani G, Di Saverio S, Gazzotti F, Lazzareschi $D$ and Pinna AD. A prospective, multi centre, randomized clinical study to compare the efficacy and safety of Ertapenem 3 days versus Ampicillin-Sulbactam 3 days in the treatment of localized community acquired intra-abdominal infection. (T.E.A. Study: Three days Ertapenem vs three days Ampicillin-sulbactam). BMC Gastroenterol. 2011; 11:42. | Article | PubMed Abstract | PubMed Full $\underline{\text { Text }}$

36. Powell LL and Wilson SE. The role of beta-lactam antimicrobials as single agents in treatment of intra-abdominal infection. Surg Infect (Larchmt). 2000; 1:57-63. | Article | PubMed

37. Oliak D, Yamini D, Udani VM, Lewis RJ, Arnell T, Vargas H and Stamos MJ. Initial nonoperative management for periappendiceal abscess. Dis Colon Rectum. 2001; 44:936-41. | Article | PubMed

38. Brown CV, Abrishami M, Muller M and Velmahos GC. Appendiceal abscess: immediate operation or percutaneous drainage? Am Surg. 2003; 69:829-32. I Article I PubMed

39. Sartelli M, Catena F, Coccolini F and Pinna AD. Antimicrobial management of intra-abdominal infections: literature's guidelines. World J Gastroenterol. 2012; 18:865-71. | Article | PubMed Abstract | PubMed Full Text

40. Roggo A, Wood WC and Ottinger LW. Carcinoid tumors of the appendix. Ann Surg. 1993; 217:385-90. | Article | PubMed Abstract | PubMed Full Text

41. Lai HW, Loong CC, Tai LC, Wu CW and Lui WY. Incidence and odds ratio of appendicitis as first manifestation of colon cancer: a retrospective analysis of 1873 patients. J Gastroenterol Hepatol. 2006; 21:1693-6. | Article I PubMed

42. Bixby SD, Lucey BC, Soto JA, Theysohn JM, Ozonoff A and Varghese JC. Perforated versus nonperforated acute appendicitis: accuracy of multidetector CT detection. Radiology. 2006; 241:780-6. | Article | PubMed

43. Tsuboi M, Takase K, Kaneda I, Ishibashi T, Yamada T, Kitami M, Higano $\mathrm{S}$ and Takahashi S. Perforated and nonperforated appendicitis: defect in enhancing appendiceal wall--depiction with multi-detector row CT. Radiology. 2008; 246:142-7. I Article | PubMed

44. Allescher HD. Appendicitis: can immediate antibiotic treatment still be withheld? Gastroenterology. 2012; 142:666-9. | Article I PubMed

45. van Tuijn CF, Luitse JS, van der Valk M, van Wissen S, Prins $M$, Rosmulder R and Geerlings SE. Reduction of the door-to-needle time for administration of antibiotics in patients with a severe infection: a tailored intervention project. Neth J Med. 2010; 68:123-7. | Article | PubMed

46. Clarke RT, Warnick J, Stretton K and Littlewood TJ. Improving the immediate management of neutropenic sepsis in the UK: lessons from a national audit. Br J Haematol. 2011; 153:773-9. I Article I PubMed

47. Andersson $M$ and Andersson RE. The appendicitis inflammatory response score: a tool for the diagnosis of acute appendicitis that outperforms the Alvarado score. World J Surg. 2008; 32:1843-9. | Article | PubMed

48. M Pisano and L Ansaloni. The ASAA-Study. Antibiotics vs. Surgery in Acute Appendicitis: an intention to treat prospective randomised controlled study. ClinicalTrials.gov Identifier: NCT01421901.

\section{Citation:}

Pisano M, Coccolini F, Poiasina E, Bertoli P, Giulii Capponi M, Poletti E, Naspro R and Ansaloni L. Conservative treatment for uncomplicated acute appendicitis in adults. Emerg Med Health Care. 2013; 1:2. http://dx.doi.org/10.7243/2052-6229-1-2 